\begin{tabular}{|c|c|c|}
\hline & Int.J.Curr.Microbiol.App.Sci (2021) 10(10): $524-532$ & \\
\hline EXCELLENT & $\begin{array}{l}\text { International Journal of Current Microbiology and Applied Sciences } \\
\text { ISSN: 2319-7706 Volume } 10 \text { Number } \mathbf{1 0}(\mathbf{2 0 2 1 )} \\
\text { Journal homepage: http://www.ijcmas.com }\end{array}$ & $\begin{array}{l}9 \\
39\end{array}$ \\
\hline PUBLISHERS & & www:ijcmas.com \\
\hline
\end{tabular}

Original Research Article https://doi.org/10.20546/ijcmas.2021.1010.062

\title{
Prevalence of ESBL and MBL Producing Acinetobacter species Isolated from Various Clinical Samples in Tertiary Care Hospital in North-West Region of Rajasthan
}

\author{
Sumitra Kumari, Sanju Pannu*, Anjli Gupta, Geeta Tinna and B.P. Sharma \\ Department of Clinical Microbiology \& Immunology, Sardar Patel Medical College, \\ Bikaner, India \\ *Corresponding author
}

Keywords

Acinetobacter, ESBL, MBL

Article Info

Accepted:

18 September 2021 Available Online:

10 October 2021

\section{A B S T R A C T}

This study was conducted with an objective to find the prevalence of extended spectrum betalactamase (ESBL) and metallo betalactamase (MBL) in Acinetobacter species. It was conducted in the Department of Microbiology, Sardar Patel Medical college, Bikaner from Feb 2018 to Feb.2019. in various clinical specimens including urine, pus, blood, vaginal swabs, respiratory samples, and various body fluids were processed Acinetobacter species isolates were identified by standard protocols. Antibiotic sensitivity testing for all isolates was done using Kirby-Bauer disc diffusion method. Disc potentiation test was performed to check ESBL and MBL production in these bacteria. Maximum ESBL and MBL positive isolates of Acinetobacter species were observed among E.T. tube samples. Early detection, stringent antibiotic policies, and compliance towards infection control practices are the best defenses against this organisms.

\section{Introduction}

Resistant bacteria are emerging world wide as a threat to the favourable outcome of common infections in the community and hospital setting. $\beta$-lactamases production by several gram negative and gram positive organisms is perhaps the most important single mechanism of resistance to penicillin cephalosporin, monobactams and carbapenems ${ }^{1,2,3}$. Among the wide array of antibiotics, beta-lactams are the most widely used agents. The most common cause of resistance to beta-lactam antibiotics is the production of betalactamases. Extended spectrum betalactamases (ESBLs) and metallo betalactamases $(\mathrm{MBL})$ represent a major group of beta-lactamases currently being identified world-wide in large numbers, most commonly produced by Acinetobacter species but also occur in other gram negative bacteria. ${ }^{4,5}$ One of the most important mechanisms of 
microbial resistance to beta-lactam antibiotics (penicillins, cephalosporins, monobactams and carbapenems) is hydrolysis by betalactamases. The accurate identification and reporting of ESBL and MBL producing Acinetobacter species will be helpful to infection control practitioners in preventing the spread of these multidrug resistant isolates. ${ }^{6,7}$ Till date no enough study have been undertaken on prevalence of ESBL and MBL producing Acinetobacter species in the state of rajasthan, therefore the present study is undertaken to find the prevalence of ESBL and MBL producing Acinetobacter species isolated in the north west region of rajasthan.

\section{Materials and Methods}

The present study was conducted in Department of Microbiology, Sarder Patel Medical College, Bikaner from Feb 2018 to Feb 2019 to detect prevalence of ESBL and MBL producing Acinetobacter species in various clinical specimens such as blood, urine, pus, CSF, throat swab, vaginal swab, sputum, pleural fluid, broncho-alveolar lavage, bronchial aspirate samples etc. received from patients admitted in different wards at P.B.M. hospital and associate group of hospitals were included in this study.

Medical and demographic data of the patients were collected using a questionnaire. Data recorded were: demographic characteristics (age, gender); immune suppression, septicaemia, burn, malignancy, recent surgery (within one month), previous treatment with broad-spectrum antibiotics, use of invasive devices, fecal colonization with Acinetobacter, and prolonged hospital (> one week) or ICU stays.

After collection the samples were processed for the identification of organisms by the conventional biological tests. ${ }^{8}$ All isolates were cultured on Mac conkey agar and blood agar and urinary isolates on Hi-chrome UTI media (obtained from Hi-Media, Mumbai, India) also incubated at $37^{\circ} \mathrm{C}$ for 24 hours. They are identified to species level by their characteristic appearances on the media, Gram's staining, catalase test, oxidase test, motility test, nitrate reduction test and Acinetobacter species were confirmed by indole test, methyl red test, citrate utilization test, urease production test, triple sugar Iron reaction, gelatin liquification test and by sugar fermentation test.

The isolates were tested for antimicrobial susceptibility, on Muller hinton agar by Kirby Bauer disk diffusion method with a inoculums matched with 0.5 McFarland turbidity standard as per CLSI recommendation ${ }^{9}$. The zone of inhibition was measured and reported as susceptible, intermediate or resistant according to standard zone size. For statistical purposes data were categorized as susceptible and non-susceptible (including intermediate and resistant groups). ${ }^{9,10}$

For Control Acinetobacter spp. (Ac. Baumanii) ATCC 19606 were used to check the potency of the disc and were used with every batch of antibiotic sensitivity testing.

Following antibiotic discs (obtained from HiMedia, Mumbai, India) were used for antimicrobial sensitivity testing- amikacin $(30 \mu \mathrm{g})$, piperacillin/tazobactum $(100 / 10 \mu \mathrm{g})$, tobramycin $(10 \mu \mathrm{g})$, ceftazidime $(30 \mu \mathrm{g})$, ampicillin/sulbactum $(10 / 10 \mu \mathrm{g}), \quad$ ceftriaxone $(30 \mu \mathrm{g})$, ciprofloxacin $(5 \mu \mathrm{g})$, levofloxacin $(5 \mu \mathrm{g})$, imipenem $(10 \mu \mathrm{g})$, meropenem $(10 \mu \mathrm{g})$, co-trimoxazole $(25 \mu \mathrm{g}), \&$ colistin $(10 \mu \mathrm{g})$. The inhibition zone diameter was measured in $\mathrm{mm}$ with the help of a special measuring scale and results recorded for each isolate separately as Sensitive, Resistant, Intermediate(S,R,I) according to the given standard zone size.

Extended Spectrum Beta Lactamases (ESBLs) 
Detection was done by Initial screening test $^{1,10}$. According to the CLSI guidelines, isolates showing inhibition zone size of $\leq 22 \mathrm{~mm}$ with Ceftazidime $(30 \mu \mathrm{g})$ and $\leq 27 \mathrm{~mm}$ with Cefotaxime $(30 \mu \mathrm{g})$ were identified as potential ESBL producers and shortlisted for confirmation of ESBL production. After screening Phenotypic confirmatory test was done with combination disk ${ }^{1,10}$. Metallo Beta Lactamases Detection was done by Initial Screening Tests: ${ }^{11}$ The isolates showing inhibition zone size of $\leq 16 \mathrm{~mm}$ with

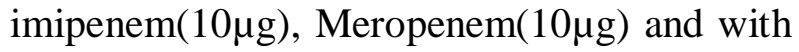
ceftazidime $(30 \mu \mathrm{g})$ were identified as MBL producers and shortlisted for confirmation of MBL production. For confirmation, phenotypic confirmatory test with combination disks ${ }^{12}$ was carried out.

\section{Results and Discussion}

Out of 100 positive cases for Acinetobacter species, $45(45 \%)$ cases were $\leq 40$ years of age and $55(55 \%)$ cases were above 40 years of age,60(60\%) were males and 40(40\%) were females.

Out of 100 isolates of Acinetobacter species, $30(30 \%)$ were found to be ESBL producers and $44(44 \%)$ were MBL producers. ESBL producing Acinetobacter species were most frequently recovered from E.T. tube $40 \%$ (12/30) followed by blood $16.67 \%$ (5/30), urine $13.33 \%(4 / 30)$, pus $13.33 \%(4 / 30)$, sputum $10 \%$ (3/30), ascitic fluid $6.67 \%(2 / 30)$ respectively.

ESBL producing Acinetobacter species were frequently recovered from E.T. tube $40 \%(12 / 30)$ followed by blood $16.67 \%$ (5/30), urine $13.33 \%(4 / 30)$, pus $13.33 \%$ (4/30), sputum 10\% (3/30), ascetic fluid 6.67\% (2/30) respectively.

MBL producing Acinetobacter species were most frequently recovered from E.T. tube $36.36 \%$ (16/44) followed by blood $20.45 \%(9 / 44)$, urine $20.45 \%(9 / 44)$, pus $9.09 \%$ (4/44), sputum $6.81 \%$ (3/44), wound swab $6.81 \%(3 / 44)$ respectively.

From clinical specimens some isolates were more sensitive while others were more resistant.

In ESBL positive (30) isolates maximum cases were from ICU 13(43.33\%) and Intubation \& Mechanical ventilation 12 (40\%). In MBL positive (44) isolates maximum cases were also from same- ICU $(19 ; 43.2 \%)$ and Intubation \& Mechanical ventilation (16; $36.4 \%$ ).

In the present study, out of 100 isolates for Acinetobacter species 55(55\%) were belonged to age group $>40$ years and $45(45 \%)$ cases were belonged to group $\leq 40$ years. This predominance was due to a weak immune system, so more risk of nosocomial infections by opportunistic microorganisms. The results are similar to other studies ${ }^{13,14,15}$, which showed that $53 \%$ to $71 \%$ isolates were belonged to $>40$ year age and $47 \%$ to $29 \%$ isolates were of $<40$ years old age group.

In the present study higher indices of Acinetobacter infection in male $60(60 \%)$ as compared to female 40 (40\%). The results are in accordance with some other studies ${ }^{13,15,16,17}$ that also showed higher incidence in males than females. 
Table.1 Distribution of ESBL producing and non-ESBL producing Acinetobacter species isolates from various clinical specimens

\begin{tabular}{|c|c|c|c|c|}
\hline S.No. & $\begin{array}{c}\text { Clinical } \\
\text { samples }\end{array}$ & $\begin{array}{c}\text { Total Acinetobacter } \text { sp. } \\
\text { Isolates (\%) }\end{array}$ & $\begin{array}{c}\text { ESBL positive } \\
\text { isolates (\%) }\end{array}$ & $\begin{array}{c}\text { ESBL negative } \\
\text { isolates (\%) }\end{array}$ \\
\hline $\mathbf{1 .}$ & E.T. tube & $32(32 \%)$ & $12(40 \%)$ & $20(28.57 \%)$ \\
\hline $\mathbf{2 .}$ & Blood & $19(19 \%)$ & $5(16.67 \%)$ & $14(20 \%)$ \\
\hline $\mathbf{3 .}$ & Urine & $17(17 \%)$ & $4(13.33 \%)$ & $13(18.57 \%)$ \\
\hline $\mathbf{4 .}$ & Pus & $11(11 \%)$ & $4(13.33 \%)$ & $7(10 \%)$ \\
\hline $\mathbf{5 .}$ & Sputum & $9(9 \%)$ & $3(10 \%)$ & $6(8.57 \%)$ \\
\hline $\mathbf{6 .}$ & Wound swab & $7(7 \%)$ & - & $7(10 \%)$ \\
\hline $\mathbf{7 .}$ & Ascitic fluid & $5(5 \%)$ & $2(6.67 \%)$ & $3(4.29 \%)$ \\
\hline $\mathbf{8 .}$ & Total & 100 & 30 & 70 \\
\hline
\end{tabular}

Table.2 Distribution of MBL producing and non-MBL producing Acinetobacter species isolates from various clinical specimens

\begin{tabular}{|c|c|c|c|c|}
\hline S.No. & $\begin{array}{c}\text { Clinical } \\
\text { samples }\end{array}$ & $\begin{array}{c}\text { Total Acinetobacter sp. } \\
\text { Isolates (\%) }\end{array}$ & $\begin{array}{c}\text { MBL positive } \\
\text { isolates (\%) }\end{array}$ & $\begin{array}{c}\text { MBL negative } \\
\text { isolates(\%) }\end{array}$ \\
\hline $\mathbf{1 .}$ & E.T. tube & $32(32 \%)$ & $16(36.36 \%)$ & $16(28.57 \%)$ \\
\hline $\mathbf{2 .}$ & Blood & $19(19 \%)$ & $9(20.45 \%)$ & $10(17.86 \%)$ \\
\hline 3. & Urine & $17(17 \%)$ & $9(20.45 \%)$ & $8(14.29 \%)$ \\
\hline $\mathbf{4 .}$ & Pus & $11(11 \%)$ & $4(9.09 \%)$ & $7(12.5 \%)$ \\
\hline $\mathbf{5 .}$ & Sputum & $9(9 \%)$ & $3(6.81 \%)$ & $6(10.71 \%)$ \\
\hline $\mathbf{6 .}$ & Wound swab & $7(7 \%)$ & $3(6.81 \%)$ & $4(7.14 \%$ \\
\hline $\mathbf{7 .}$ & Ascitic fluid & $5(5 \%)$ & - & $5(8.93 \%)$ \\
\hline $\mathbf{8 .}$ & Total & 100 & 44 & 56 \\
\hline
\end{tabular}

Table.3 Antimicrobial susceptibility pattern of Acinetobacter species

\begin{tabular}{|c|c|c|c|}
\hline S.No. & Antibiotics & $\begin{array}{c}\text { Sensitive isolates } \\
(\mathbf{\%})\end{array}$ & $\begin{array}{c}\text { Resistant isolates } \\
(\mathbf{\%})\end{array}$ \\
\hline $\mathbf{1 .}$ & Amikacin(AK) & $55 \%$ & $45 \%$ \\
\hline $\mathbf{2 .}$ & Piperacillin/tazobactam(PIT) & $62 \%$ & $38 \%$ \\
\hline $\mathbf{3 .}$ & Tobramicin(TOB) & $37 \%$ & $63 \%$ \\
\hline $\mathbf{4 .}$ & Ampicillin/Sulbactam(AMS) & $47 \%$ & $53 \%$ \\
\hline $\mathbf{5 .}$ & Ceftazidime(CAZ) & $37 \%$ & $63 \%$ \\
\hline $\mathbf{6 .}$ & Ceftriaxone(CTR) & $17 \%$ & $83 \%$ \\
\hline $\mathbf{7 .}$ & Ciprofloxacin(CIP) & $55 \%$ & $45 \%$ \\
\hline $\mathbf{8 .}$ & Levofloxacin(LE) & $50 \%$ & $50 \%$ \\
\hline $\mathbf{9 .}$ & Imipenem(IPM) & $52 \%$ & $48 \%$ \\
\hline $\mathbf{1 0 .}$ & Co-trimoxazole(COT) & $52 \%$ & $48 \%$ \\
\hline $\mathbf{1 1 .}$ & (trimethoprim/sulphamethoxazole) & & $2 \%$ \\
\hline $\mathbf{1 2 .}$ & Colistin(CL) & $98 \%$ & $35 \%$ \\
\hline
\end{tabular}


Table.4 Association of risk factors with ESBL production and MBL production

\begin{tabular}{|c|c|c|c|c|c|}
\hline S.No & Risk factors & $\begin{array}{c}\text { ESBL } \\
\text { positive } \\
\text { isolates( \%) }\end{array}$ & $\begin{array}{c}\text { ESBL } \\
\text { negative } \\
\text { isolates(\%) }\end{array}$ & $\begin{array}{c}\text { MBL } \\
\text { positive } \\
\text { isolates(\%) }\end{array}$ & $\begin{array}{c}\text { MBL } \\
\text { negative } \\
\text { isolates(\%) }\end{array}$ \\
\hline $\mathbf{1 .}$ & ICU stay & $13(43.33 \%)$ & $30(42.86 \%)$ & $19(43.18 \%)$ & $24(42.86 \%)$ \\
\hline $\mathbf{2 .}$ & Recent surgery & $08(26.67 \%)$ & $14(20 \%)$ & $09(20.45 \%)$ & $13(23.21 \%)$ \\
\hline $\mathbf{3 .}$ & $\begin{array}{c}\text { Use of invasive } \\
\text { devices (urinary } \\
\text { catheterization) }\end{array}$ & $05(16.67 \%)$ & $12(17.14 \%)$ & $09(20.45 \%)$ & $08(14.28 \%)$ \\
\hline 4. & $\begin{array}{c}\text { Use of broadspectrum } \\
\text { antibiotics }\end{array}$ & $02(6.67 \%)$ & $06(8.57 \%)$ & $02(4.54 \%)$ & $06(10.71 \%)$ \\
\hline $\mathbf{5 .}$ & $\begin{array}{c}\text { Intubation \& } \\
\text { Mechanical ventilation }\end{array}$ & $12(40 \%)$ & $20(28.57 \%)$ & $16(36.36 \%)$ & $16(28.57 \%)$ \\
\hline $\mathbf{6 .}$ & $\begin{array}{c}\text { Prolonged hospital } \\
\text { stay }\end{array}$ & $02(6.67 \%)$ & $05(7.14 \%)$ & $04(9.09 \%)$ & $03(5.36 \%)$ \\
\hline $\mathbf{7 .}$ & Immune suppression & $02(6.67 \%)$ & $01(1.42 \%)$ & - & $03(5.36 \%)$ \\
\hline $\mathbf{8 .}$ & Old age & $10(33.33 \%)$ & $15(21.43 \%)$ & $10(22.72 \%)$ & $15(26.78 \%)$ \\
\hline
\end{tabular}

Fig.1 Antimicrobial susceptibility of ESBL and MBL producing strain on MHA showing resistance to ceftazidime (CAZ) and imipenem (IPM)

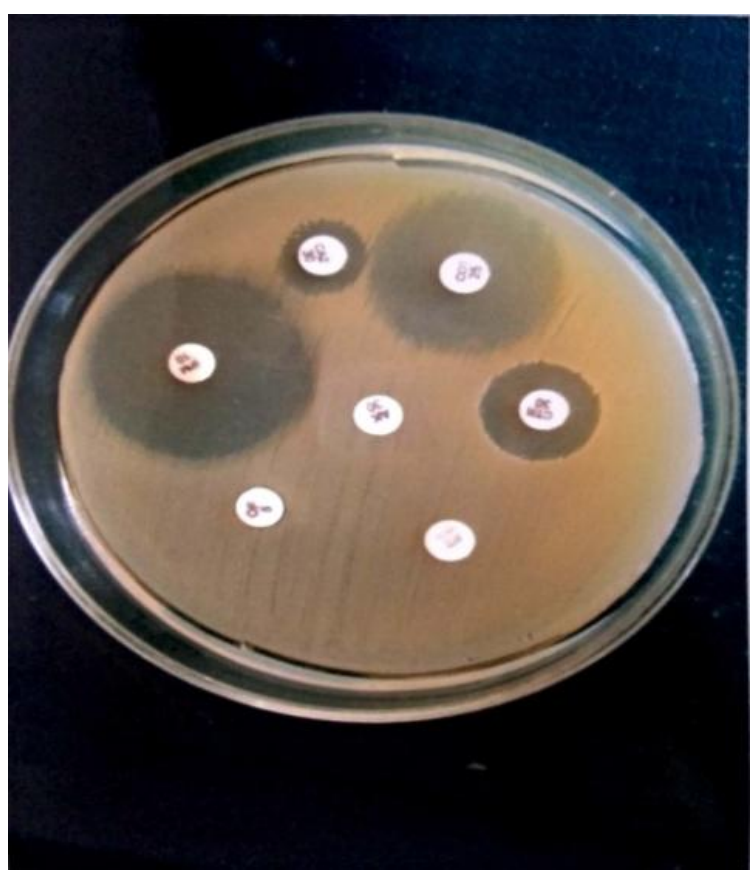


Fig.2 Combination disc method of MBL confirmation showing $>7 \mathrm{~mm}$ increase in zone size around imipenem + EDTA

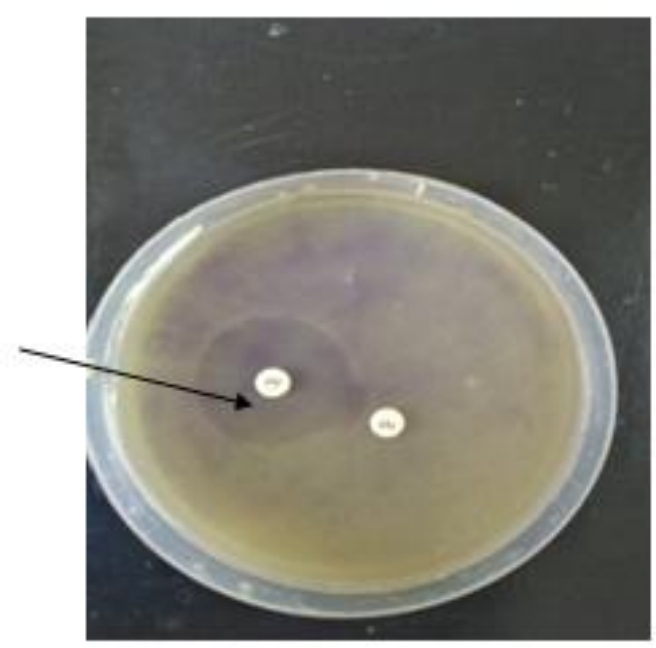

Fig.3 Combination disc method of ESBL confirmation showing $>5 \mathrm{~mm}$ increase in zone size around ceftazidime + clavulanic acid (CAC)

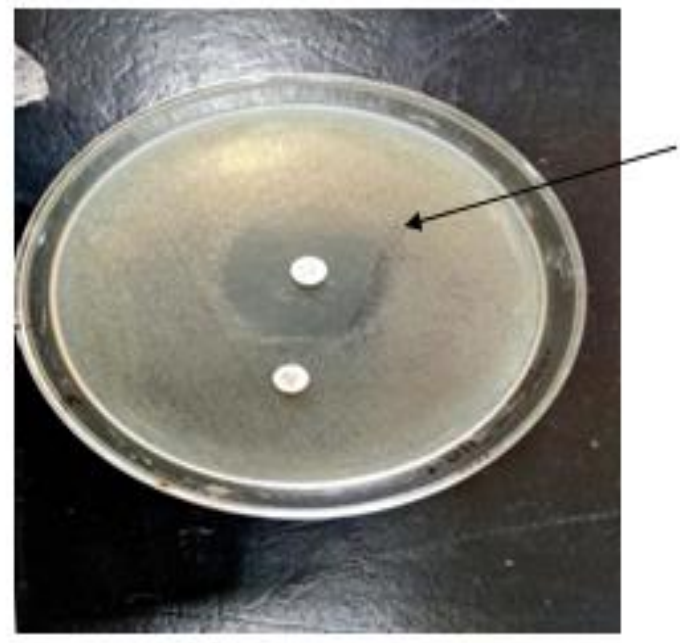

In the present study, $30 \%$ isolates of Acinetobacter species were positive for ESBL production and $44 \%$ isolates were positive for MBL production. These results are similar to study by Purti Tripathi et al., (2013) ${ }^{18}$ who had reported ESBL production in Acinetobacter species was $29 \%$ and MBL production was 37\%, Harekrishna Nath et al., $(2016)^{15}$ who had reported ESBL production was $32 \%$ and MBL production was $38 \%$.

In the present study ESBL- producing Acinetobacter species were recovered most frequently from E.T.tube (40\%) followed by blood (16.67\%), similar observations were made by Molay Banerjee et al., (2013) ${ }^{14}$ who had reported ESBL producing Acinetobacter species were recovered most frequently from E.T. Tube (35.29\%) followed by blood (14.70\%), Amandeep Kaur et al., (2018) ${ }^{19}$ who had reported $(37.5 \%)$ from E.T. tube followed by (9.3\%) from blood, Nashwa M. et al., $(2017)^{20}$ reported (39.3\%) from E.T.tube.

In the present study MBL-producing 
Acinetobacter species were recovered most frequently from E.T. tube $(36.36 \%)$ followed by blood $(20.45 \%)$ and urine $(20.45 \%)$ similar observations were made by Molay banerjee et al., $\quad(2013)^{14}$ who had reported MBL producing Acinetobacter species were recovered most frequently from E.T.tube $(43.75 \%)$ followed by blood $(12.5 \%)$ and urine(12.5\%), Amandeep kaur et al.,(2018) ${ }^{19}$ who had reported $(32.63 \%)$ from E.T.tube followed by blood (5.7\%) and urine (11.53\%), Muneeza Anwar et al., (2016) ${ }^{21}$ also reported $(18.2 \%)$ from blood and $(21.2 \%)$ from urine.

In the present study $55 \%$ isolates of Acinetobacter species were susceptible to Amikacin. The results are similar to Purti Tripathi et al., (2013) ${ }^{18}$ who had reported $55.14 \%$ susceptibility to amikacin, Harekrishna nath et al.,(2016) ${ }^{15}$ who had reported $57.15 \%$ susceptibility, Amandeep kaur et al., (2018) ${ }^{19}$, S john et al., (2011) $)^{22}$ and Mahua sinha et al., $(2007)^{23}$ who have reported $60.3 \%, 43.3 \%$ and $33 \%$ susceptibility respectively.

In the present study $62 \%$ isolates of Acinetobacter species were susceptible to piperacillin/tazobactam. The results are similar to Molay banerjee et al., (2013) ${ }^{14}$ who had reported $65.33 \%$ susceptibility to piperacillin/tazobactam, Amandeep kaur et al., (2018) ${ }^{19}$ and Gunjan Shrivastava et al., $(2013)^{24}$ who have reported $64.6 \%$ and $62 \%$ susceptibility respectively.

In the present study sensitivity of other drugs like Tobramicin, Ampicillin/sulbactam, Ceftazidime, Ceftriaxone, Ciprofloxacin, Levofloxacin (LE), Imipenem (IPM), CoTrimoxazole (COT), Colistin (CL), Meropenem (MRP) is almost similar to findings of Gunjan Shrivastava et al., $(2013)^{24}$, Richa gupta et al., (2014) ${ }^{25}$, Amir peymani et al., $(2011)^{26}$, Banerjee et al., $(2013)^{14}$, Mahua Sinha et al., (2007) ${ }^{23}$ and Amandeep kaur et al., (2018) ${ }^{19}$, Harekrishna nath et al., (2016) ${ }^{15}$ etc.

In the present study total in 30\% ESBL producing Acinetobacter species, 13(43.33\%) were isolated from ICU patients followed by $08(26.67 \%)$ in recent surgery patients, $05(16.67 \%)$ patients with invasive medical devices(urinary cathetrization), 02 (6.67\%) patients with use of broad spectrum antibiotics, $12(40 \%)$ patients with intubation \& mechanical ventilation, 02(6.67\%) patients with prolonged hospital stay, 02(6.67\%) patients with immune suppression, $10(33.33 \%)$ in old age patients. Similar observation were made by Mahua sinha et al., $(2007)^{23}$ where $38 \%$ isolates were obtained from patients admitted in ICU followed by $22 \%$ in recent surgery patients, $18 \%$ patients with use of broad spectrum antibiotics respectively. Bhattacharyya et al., $(2013)^{16}$ also reported $40 \%$ isolates were obtained from patients admitted from ICU followed by $18 \%$ in recent surgery patients, $13 \%$ patients with use of broad spectrum antibiotics respectively.

In the present study total in $44 \% \mathrm{MBL}$ producing Acinetobacter species, 19(43.18\%) were isolated from ICU patients followed by $09(20.45 \%)$ in recent surgery patients, $09(20.45 \%)$ patients with invasive medical devices (urinary cathetrization), 02(4.54\%) patients with use of broad spectrum antibiotics, $16(36.30 \%)$ patients with intubation \& mechanical ventilation, 04(9.09\%) patients with prolonged hospital stay, $10(22.72 \%)$ in old age patients. Similar observation were made by Harekrishna nath $e t$ al., (2016) ${ }^{15}$ where $42 \%$ isolates were obtained from patients admitted in ICU followed by $18 \%$ in recent surgery patients, $34 \%$ patients with intubation and mechanical ventilation respectively. $\mathrm{R}$ moniri et al., $(2010)^{17}$ also reported $86.7 \%$ isolates from ICU followed by $15 \%$ in recent surgery patients, $22 \%$ patients with intubation and mechanical ventilation respectively. 
A total of 100 clinical isolates of Acinetobacter species recovered from various clinical specimens from all ages and both sexes were studied, Among these isolates 30 were found to be ESBL producer and 44 were MBL producer. As ESBL and MBL producing isolates occur in large number of patients and show false susceptibility to extended spectrum cephalosporins and imipenem in standard disk diffusion method, therefore cephalosporins and aztreonam should not be given on the basis of routine susceptibility test results. Acinetobacter species were highest recovered from ICU patients followed by intubation and mechanically ventilated patients and least isolates were recovered from immune suppression and prolonged hospital stay patients.

\section{Acknowledgements}

I am sincerely thankful to the all authors for their valuable support.

\section{References}

1. Agrawal P, Ghosh A N, Kumar S, Basu B, Kapila K. Prevalence of extended-spectrum beta-lactamases among Escherichia coli and klebsiella pneumonia in a tertiary care hospital. Indian J Patho Microbiol 2008;51:139-142

2. Kumar M S Lakshmi V, Rajagopalan R. Occurance of ESBL among Enterobacteriace spp. Isolated at a tertiary care institute. Indian J Med Microbiol 2006;24(3):208-211

3. Rodrigues C, Joshi P, Jani S H, Alphonse M, Radhakrishnan R, Metha A. Detection of betalactamases in nosocomial gram-negative clinical isolates. Indian $\mathrm{J}$ Med Microbiol 2004;22(4):247-250

4. Singhal S, Mathur T, Khan S, Upadhyay D J, Gaind R, Rattan A. Evaluation of methods for Amp-c beta-lactamases in gram-negative clinical isolates from tertiary care Hospital. Indian J Med Microbiol 2005;23(2):120-124

5. Kader A A, Kumar A. Prevalence and antimicrobial susceptibility of ESBL producing Escherichia coli and Klebsiella pneumoniae in a general hospital. Ann. Saudi Med 2005;25(3):239-242.

6. Shobha K L, Ramachandra L, Rao G, Majumder S, Rao S P. Extended-spectrum $\beta$ lactamases in gram negative bacilli at a tertiary care hospital. Journal of clinical and Diagnostic Research 2009; 3 : 1307-1312

7. Senda, K., Y. Arakawa, K. Nakashima, H. Ito, S. Ichiyama, K. Shimokata, N. Kato and M. Otha. Multifocal outbreaks of metallo $\beta$. lactamases producing pseudomonas aeruginosa resistant to broad-spectrum $\beta$ lactams, including carbapenems. Antimicrob. Agents Chemother 1996; 40 : 349-353

8. Patrick R M. Manual of Clin Microbial 2007. $9^{\text {th }}$ ed. Asm press, Washington D.C.,USA.

9. National committee for clinical laboratory standards (2005): performance standards for antimicrobial susceptibility testing; $15^{\text {th }}$ information supplement(M100-S15). National committee for lab standards, Wayne, $\mathrm{Pa}$.

10. Winn W C, J R, Allen S D, Janda W M, Koneman E W, Procop G W, Schreckenberger P C, Woods G L. Koneman's color atlas and text book of diagnostic Microbiology. $6^{\text {th }}$ ed. Philadelphia: LIPPINCOTT WILLIAMS \& WILKINS, 2006.p.1003

11. Bhalerao D S, Roushani S, Kinikar A G, Akhter I. Study of Metallo beta-lactamases producing pseudomonas aeruginosa in Pravara Rural Hospital. Pravara Med Rev 2010;5(3).

12. Sofia Constantiniu, Amgela Romaniuc, Luminita Smaranda Iancu, Raluca Filimon, Iuliana Tarasi. Cultural and biochemical characteristics of Acinetobacter spp. Strains. The $\mathrm{J}$ of preventative medicine 2004; 12(34):35-42.

13. Geeta Tinna, Veenu Sawaria, Anjli Gupta, B. P. Sharma. Study of prevalence and antimicrobial susceptibility pattern of Acinetobacter species isolated from various clinical specimens in tertiary care institute in north west region of rajasthan. IJSR 2015;4(10):521-522.

14. Molay Banerjee, B. L. Chaudhary, Snehanshu Shukla, Prevalence of ESBL and MBL in Acinetobacter species isolated from clinical samples in tertiary care hospital. International journal of science \& research. 2013 ; 6: 1183- 
1187.

15. Harekrishna Nath and Dipa Barkataki, Prevalence of ESBL and MBL producing Acinetobacter isolates in clinical specimens in tertiary care hospital, Assam, India. International journal of current microbiology and applied sciences. 2016; 5: 515-522.

16. Bhattacharyya S, Bhattacharyya I, Rit K, Mukhopadhyay P K, Dey J B, Ganguly U, Ray R. Department of Microbiology, Bankura Sammilani Medical college, Bankura, West Bangal, India. Antibiogram of Acinetobacter spp. isolated from various clinical specimens in a tertiary care hospital in West Bengal, india Biomedical Research 2013;24(1):43-46 ISSN 0970-938X.

17. R Moniril, R kheltabadi Farahani I, Gh Shajaril, M H. Nazem Shirazi, A Ghasemil molecular epidemiology of Aminoglycosided resistance in Acinetobacter spp. With Emergence of multidrug resistant strains Iranian J Publ Health, vol.39, No.2,2010,pp6368.

18. Purti Tripathi, Sunita Gajbhiye, Prevalence of multidrug resistance ESBL and MBL production in Acinetobacter species, international journal of recent trends in sciences and technology. 2013; 6: 139-143.

19. Amandeep kaur and satnam singh. Prevalence of ESBL and MBL producing pseudomonas aeruginosa and Acinetobacter baumannii isolated from various clinical sample. $\mathrm{J}$ of pathogens 2018;7.

20. Nashwa M. Alkasaby and Mayasaa E L Sayed Zaki. Molecular study of Acinetobacter baumannii isolates for metallo- $\beta$-lactamases and extended spectrum beta-lactamases genes in intensive care unit, Mansoura university hospital, Egypt. Int J of Micro,2017.

21. Muneeza Anwar, Hassan Ejaz, Aizza Zafar and hamdan Hamid. Phenotypic detection of metallo-beta-lactamases in Carbapenem resistant Acinetobacter baumannii isolated from pediatric in Pakistan. J of pathogen,2016.

22. S John, Balagurunathan R. MBL producing Pseudomonas aeruginosa and Acinetobacter baumannii. IJMM 2011;29(3):302-4.

23. Mahua Sinha, H.Srinivasa \& R. Macaden, Antibiotic Resistant Profile \& ESBL Production in Acinetobacter Species, Indian Journal of Medical Research. 2007; 126: 6367.

24. Gunjan shrivastava, Ganesh S. Bhatambare, Trupti Bajpal, Kamlesh B. Patel. Sensitivity profile of multidrug resistant Acinetobacter spp. Isolated at ICUs of tertiary care hospital. IJ of health system and Disaster Management2013;1(4).

25. Richa gupta, Abida Malik, Meher Rizvi \& Moied Ahmed. Presence of MBL,ESBL, AmpC positive non-fermenting Gram-negative bacilli among ICU patients with special

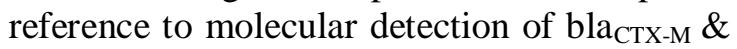
bla $_{\text {AmpC }}$ genes. I J Med Res 2016;144:271-275.

26. Amir Peymani, Mohammad-Reza Nahaei, Safar Farajnia, Alka Hasani, Akbar Mirsalehina, Nasrollah Sohrabi and Laleh Abbasi, High Prevalence of MBL Acinetobacter baumannii in a Teaching Hospital in Tabriz, Iran. Jpn. J. Infect. Dis., 2011; 64: 69-71.

\section{How to cite this article:}

Sumitra Kumari, Sanju Pannu, Anjli Gupta, Geeta Tinna and Sharma, B.P. 2021. Prevalence of ESBL and MBL Producing Acinetobacter Species Isolated from Various Clinical Samples in Tertiary Care Hospital in North-West Region of Rajasthan. Int.J.Curr.Microbiol.App.Sci. 10(10): 524-532. doi: https://doi.org/10.20546/ijcmas.2021.1010.062 